\title{
Simulation of a vehicle passage through an individual road irregularity
}

\author{
Ján Dižo ${ }^{1,{ }^{*}, \text { Miroslav Blatnický }}{ }^{1}$, Rafał Melnik ${ }^{2}$, Stanislav Semenov ${ }^{3}$, Evgeny Mikhailov $^{3}$ \\ , and Peter Gasper ${ }^{1}$ \\ ${ }^{1}$ University of Žilina, Faculty of Mechanical Engineering, Univerzitná 8215/1, 01026 Žilina, Slovak \\ Republic \\ ${ }^{2}$ Lomza State University of Applied Sciences, Faculty of Computer Science and Food Science, \\ Akademicka St. 14, 18-400 Lomza, Poland \\ ${ }^{3}$ Volodymyr Dahl East Ukrainian National University, Department of Logistics and Traffic Safety, \\ Central Avenue 59A/403, 93400 Severodonetsk, Ukraine
}

\begin{abstract}
Investigation of mechanical vibration of a vehicle is still current topic. This phenomenon effects dynamic properties of the vehicle. Mechanical vibration of vehicles during running are caused mainly due to road irregularities. Vibrations are signified as deflections of individual parts of a vehicles. Depending on deflection magnitude, they can be perceived only as slight oscillations or, in case of rough terrain and higher running speed as significant shocks leading to adverse passenger comfort, decreased driving safety and extraordinary loading of a road. The article presents a simplified way to analyse the vehicle running through a road irregularity using mathematical approach as well as results of dynamic analysis of a vehicle computational model for running through a road irregularity.
\end{abstract}

\section{Introduction}

Generally, a vehicle represents a quite complicated mechanical system, which consists of bodies interconnected by coupling elements. During the running, large number of external factors (roadway surface quality, vehicle running speed, road profile etc.) and internal factors (weight, location of the centre of gravity, dimension of a vehicle etc.) effect to the vehicle running behaviour [1-3]. We can imagine a four-wheel vehicle as a system, which consist of five individual bodies, i.e. a bodywork and four wheels connected to each other by a suspension system, springs and dampers. In the reality, a vehicle also includes another components, such as a drive-train system, a cabin, etc., which increase system complexity [4-6]. Then, large number of equations of motion are needed for the description of the vehicle motions in a space. Therefore, in the analytical approach, certain simplifications are allowed and partial problems are investigated. In the other hand if the simulation software is used, the vehicle mechanical system can be modelled more complex and more phenomena related with the vehicle running of a road can be evaluated [7-9].

\footnotetext{
* Corresponding author: jan.dizo@ffstroj.uniza.sk
} 


\section{Mathematical description of passage of a simplified 2-DOF vehicle through an individual road irregularity}

For analytical description of vertical vehicle dynamics, we can consider a simplified planar model of a vehicle with two degrees of freedom. Such a model consists of two masses linked by springs and dampers. This vehicle passes through uneven terrain. The task is to investigate a response of the vehicle system to this phenomenon [10-12].

A mass $m_{1}$ represents unsprung masses (a wheel, a part of a vehicle suspension), $m_{2}$ are sprung masses (a car body), $k_{1}, k_{2}, b_{1}$ and $b_{2}$ are stiffness and damping coefficient of tyres and suspension system, respectively. Deflections $z_{1}$ and $z_{2}$ are measured from an equilibrium state. As we consider a linear model, gravitational forces of masses $G_{1}$ and $G_{2}$ can be neglected. Thus, resulting deflections are given by a sum of static and dynamic deflections. The road irregularity is described by the formulation $s=s(\xi)$ and for a constant speed $v \xi=$ $v \cdot t$. The function $s=s(v \cdot t)$ represents a kinematic excitation of the vehicle mechanical system $[13,14]$.

The system of equations of motions describing its behaviour are as following:

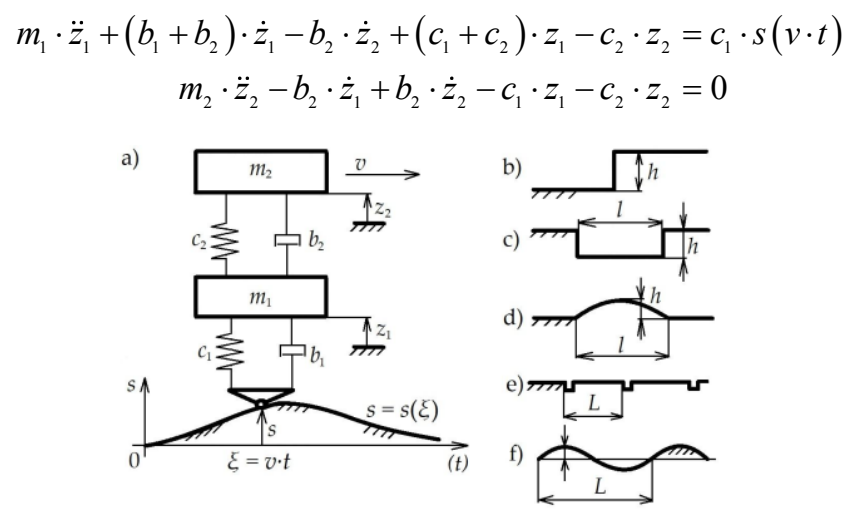

Fig. 1. Passage of a 2-DOF model of a vehicle through a road irregularity, various kind of road irregularities.

The function (1) has a special form for a particular road irregularity. Examples are shown in Fig. 1b) to f). If we will solve the case in Fig. 1b) damping will be neglected, the Laplace transform as following:

$$
L\{f(t)\}=\int_{0}^{\infty} f(t) \cdot e^{-p \cdot t} \cdot d t=F(p), L^{-1}\{F(p)\}=f(t)
$$

will be considered and the simplified equations of motion (for $b_{1}=b_{2}=0$ ) will be processed by the Laplace transform, for zero initial conditions, we get:

$$
\begin{gathered}
m_{1} \cdot p^{2} \cdot X_{1}(p)+\left(c_{1}+c_{2}\right) \cdot X_{1}(p)-c_{2} \cdot X_{2}(p)=c_{1} \cdot h \cdot \frac{1}{p} \\
m_{2} \cdot p^{2} \cdot X_{2}(p)+c_{2} \cdot X_{2}(p)-c_{2} \cdot X_{1}(p)=0
\end{gathered}
$$

It is (3) a system of two algebraic equations for unknown functions $X_{1}(p)$ and $X_{2}(p)$. We write a determinant of the system (3) using the angular eigenfrequencies $\Omega$ and $\Omega$.

Searched functions $X_{1}(p)$ and $X_{2}(p)$ we get using the Cramer's rule. Then, we perform the inverse Laplace transform by means of a decompositions to partial fractions, and finally, using the operators, we determine deflections as time functions: 


$$
\begin{aligned}
& z_{1}(t)=\frac{h \cdot c_{1}}{m_{1} \cdot m_{2}} \cdot\left[\frac{c_{2}}{\Omega_{1}^{2} \cdot \Omega_{2}^{2}}+\frac{c_{2}-m_{2} \cdot \Omega_{1}^{2}}{\Omega_{1}^{2} \cdot\left(\Omega_{1}^{2}-\Omega_{2}^{2}\right)} \cdot \cos \left(\Omega_{1} \cdot t\right)+\frac{m_{2} \cdot \Omega_{2}^{2}-c_{2}}{\Omega_{2}^{2} \cdot\left(\Omega_{1}^{2}-\Omega_{2}^{2}\right)} \cdot \cos \left(\Omega_{2} \cdot t\right)\right] \\
& z_{2}(t)=\frac{h \cdot c_{1} \cdot c_{2}}{m_{1} \cdot m_{2}} \cdot\left[\frac{1}{\Omega_{1}^{2} \cdot \Omega_{2}^{2}}+\frac{1}{\Omega_{1}^{2} \cdot\left(\Omega_{1}^{2}-\Omega_{2}^{2}\right)} \cdot \cos \left(\Omega_{1} \cdot t\right)+\frac{1}{\Omega_{2}^{2} \cdot\left(\Omega_{1}^{2}-\Omega_{2}^{2}\right)} \cdot \cos \left(\Omega_{2} \cdot t\right)\right]
\end{aligned}
$$

\section{Passage of a full-vehicle model through an individual road irregularity - simulations and results}

Simulation computations were performed in a commercial simulation package Simpack. This software allows to set up mechanical systems of various types, from simplified model of vehicles (road, railway) [15], their construction units [16, 17], to quite complicated vehicle combination, such as an articulated truck train, train-set etc. [18, 19]. In our case, we have created a multibody model (MBS) of an off-road vehicle. There is so-called a full-vehicle model, i.e. a spatial vehicle model. The MBS vehicle model consists of rigid bodies, which are connected to each other by means of mechanical couplings (joints), kinematic couplings (constraints) and force elements (coil springs, dampers). The vehicle is equipped by an independent front axle and a solid rear axle. Figure 2 shows the investigated vehicle model created in the Simpack software. A detail of a vehicle front axle, when it is passaging through an individual road irregularity is shown in Fig. 3a and parameters of the considered road irregularity are depicted in Fig. 3 b.

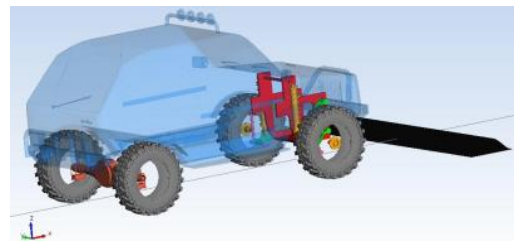

Fig. 2. An illustration of a MBS model of the investigated off-road vehicle in the Simpack software.
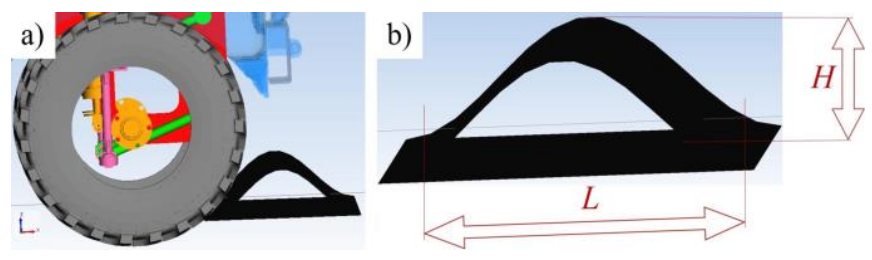

Fig. 3. a) The detail of the off-road vehicle passage through an individual road irregularity, b) parameters of an individual road irregularity.

There have been performed number of simulations for various combinations of vehicle speeds and road irregularity dimensions, from which, only some illustrative results are selected. The obtained results are shown in Fig. 4. It includes graphs of the total vertical wheel forces, which are arranged as following: the first row consist of waveforms for the height of the road irregularity $H$ of $100 \mathrm{~mm}$ and the second row for the height of $200 \mathrm{~mm}$. The length of the road irregularity $L$ has always been of $300 \mathrm{~mm}$. Three driving speeds of the vehicle have been selected for evaluation of results, namely for $15 \mathrm{~km} / \mathrm{h}, 50 \mathrm{~km} / \mathrm{h}$ and 80 $\mathrm{km} / \mathrm{h}$. 


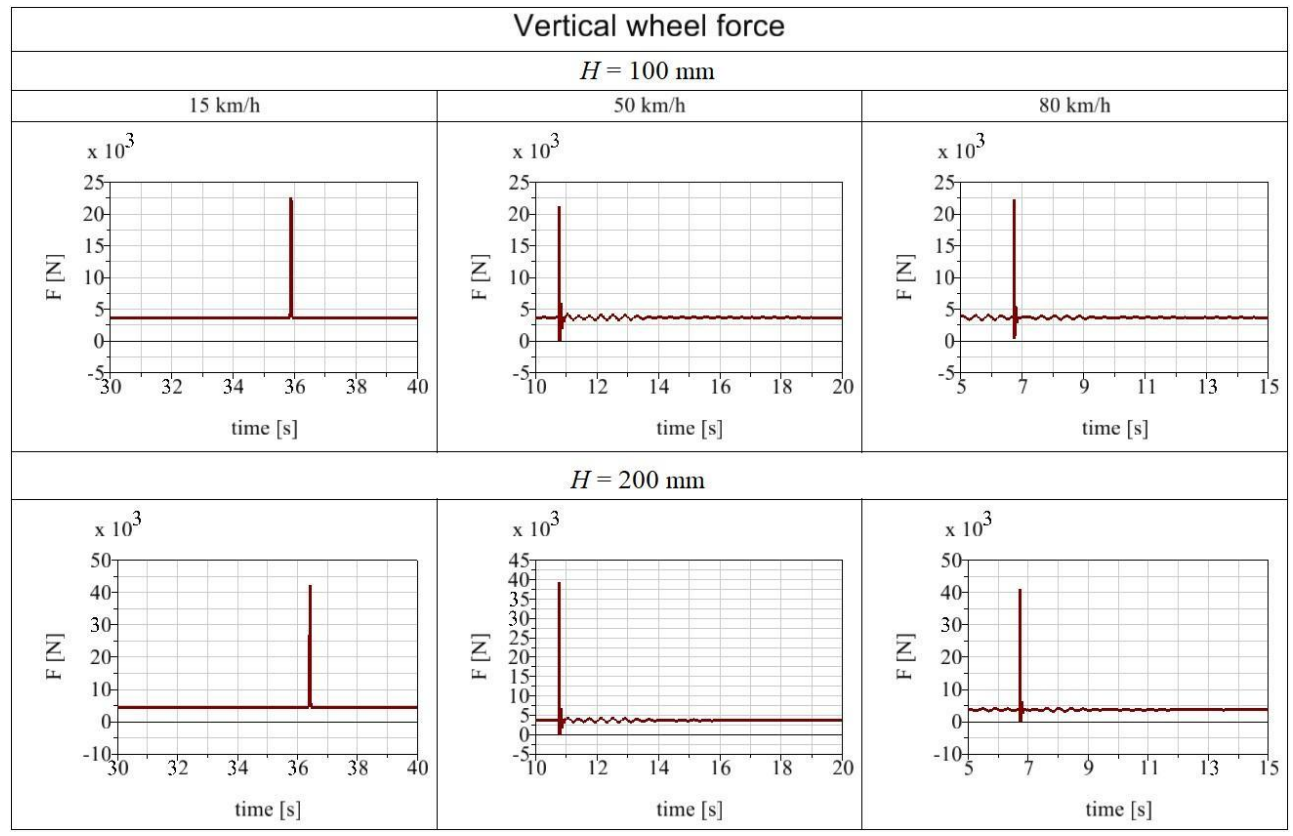

Fig. 4. Waveforms of the vertical wheel forces for different driving speeds $(15 \mathrm{~km} / \mathrm{h}, 50 \mathrm{~km} / \mathrm{h}, 80$ $\mathrm{km} / \mathrm{h}$ ) and for two height of the road irregularity $(100 \mathrm{~mm}, 200 \mathrm{~mm})$.

Let's to evaluate the results of the full-vehicle model through the individual road irregularity. When the vehicle runs through the road irregularity at the speed of $15 \mathrm{~km} / \mathrm{h}$, in the moment of passage, the total vertical force is increasing. This phenomenon occurs for all running cases. The maximal value of the total vertical wheel force for the irregularity height of 100 $\mathrm{mm}$ is about $22.6 \mathrm{kN}$, which represents more than six times the force on the even road. The force on the even road has the value of $3.696 \mathrm{kN}$ and this value correspond to the wheel static load. As we can observe on all six graphs, the value of $3.696 \mathrm{kN}$ is valid for all investigated cases. In case of the irregularity height of $200 \mathrm{~mm}$, the vertical wheel force is increasing up to the value of $44.7 \mathrm{kN}$, which is practically twice previous value.

The running speed of $50 \mathrm{~km} / \mathrm{h}$ leads to different waveforms of the vertical wheel force. While the maximal values of the forces are almost the same with the speed of $15 \mathrm{~km} / \mathrm{h}$, in this case, we can recognize greater excitation of the wheel (i.e. also the vehicle) after the passage of the road irregularity. However, there is more important the fact, that the minimal value of the vertical wheel forces for both heights of $100 \mathrm{~mm}$ and $200 \mathrm{~mm}$ at the speed of $50 \mathrm{~km} / \mathrm{h}$ equal to zero. This is the negative effect of the observed driving conditions, because zero vertical wheel force means impossibility of transmission of driving forces, but mainly the lateral and braking forces. If the vehicle would was in such a situation in the reality, it would lost handling and steerability.

Finally, we evaluate the results for the running speed of $80 \mathrm{~km} / \mathrm{h}$. This speed is quite high and is considered for comparing with a vehicle running at lower speeds. As we can see, higher running speed leads to more significant excitation of the vehicle in the transition area of the vehicle through the irregularity. Regarding to maximal and minimal values, the maximal values are similar to the previous investigated running cases. The maximal and minimal values of the vertical wheel force for the running speed of $80 \mathrm{~km} / \mathrm{h}$ also equal to zero.

\section{Conclusions}


The vehicle dynamics is an important field and still current topic, which has to be still investigated. It is influenced mainly by running speed and road quality. Lower road quality in combination with high running speed contribute to deterioration of handling and steerability of a vehicle. It is caused by the fact that vertical wheel force of a vehicle directly depends on the mentioned parameters. The decreased vertical wheel force relates with low ability to transmit drive, lateral and braking forces and negatively influences the vehicle safety.

This work was supported by the Cultural and Educational Grant Agency of the Ministry of Education of the Slovak Republic in the project No. KEGA 023ŽU-4/2020: Development of advanced virtual models for studying and investigation of transport means operation characteristics.

\section{References}

1. J. Gerlici, V. Sakhno, A. Yefymenko, V. Verbitskii, A. Kravchenko, K. Kravchenko, MATEC Web of Conferences 157 (2018)

2. T. Lack, J. Gerlici, 23rd Conference: Current Problems in Rail Vehicles, pp. 217-23 (2017)

3. M. Saga, M. Vasko, M. Handrik, P. Kopas, Scientific Journal of Silesian University of Technology 103(2019)

4. B.Leitner, Transport Means, pp. 17-20 (2010)

5. L. Gardynski, J. Caban, D. Barta, Advances in Science and Technology 12, 3 (2018)

6. O. Fomin, A. Lovska, V. Radkevych, A. Horban, I. Skliarenko, O. Gurenkova, ARPN Journal of Engineering and Applied Sciences 14, 21 (2019)

7. B. Leitner, M. Decky, M. Kovac, Transport 34, 2 (2019)

8. J. Harusinec, M. Maňuorvá, A. Suchánek, Manufacturing Technology 16, 5 (2016)

9. J. Harusinec, A. Suchanek, M. Loulova, P. Kurcik, MATEC Web of Conferences 254 (2019)

10. B. Leitner, L. Figuli, MATEC Web of Conferences 157 (2018)

11. J. Gerlici, T. Lack, Komunikacie 11, 2 (2009)

12. T. Lack, J. Gerlici, Komunikacie 10, 3 (2008)

13. M. Saga, L. Jakubovicova, Scientific Journal of Silesian University of Technology 84(2014)

14. J. Flizikowski, M. Macko, J. Czerniak, A. Mroziński, Proc. of ASME International Mechanical Engineering Congress and Exposition, pp. 1227-1235 (2012)

15. V. Hauser, O.S. Nozhenko, K.O. Kravcheko, M. Loulová, J. Gerlici, T. Lack, Manufacturing Technology 17, 3 (2017)

16. P. Baran, P. Kukuca, D. Barta, R. Labuda, P. Drozdziel, S. Pukalskas, Communications 19, 2 (2017)

17. P. Baran, P. Št’astniak, P. Kukuča, M. Brezáni, MATEC Web of Conferences 157 (2018)

18. P. Stastniak, L. Smetanka, 23rd International Conference on Current Problems in Rail Vehicles, pp. 319-328 (2019)

19. O. Fomin, A. Lovska, Engineering Science and Technology 23, 6 (2020) 